\title{
Fundamental Studies on the Interactions between Moisture and Textiles V. FT-IR Study on the Moisture Sorption Isotherm of Nylon $6^{\dagger}$
}

\author{
Mitsuhiro FuKuda, Mariko MiYagawa, ${ }^{\dagger \dagger}$ Hiromichi KawaI ${ }^{\dagger \dagger}$ \\ Noriko YAGI, ${ }^{*}$ Osamu KIMURA, ${ }^{*}$ and Toshihiko OHTA* \\ Department of Practical Life Studies, Faculty of Teacher Education, \\ Hyogo University of Teacher Education, Hyogo 673-14, Japan \\ *Research Center, Toyo-bo Co., Ltd., Ohtsu, Shiga 520-02, Japan
}

(Received October 3, 1986)

\begin{abstract}
The interaction of moisture with nylon 6 was investigated using an FT-IR spectroscopy over a near-infrared range of wavenumbers from 4500 to $8000 \mathrm{~cm}^{-1}$ to cover the first overtones of $\left(2 v_{\mathrm{CH}}\right)$ and $\left(2 v_{\mathrm{NH}}\right)$ as well as the water sensitive 5100 and $6900 \mathrm{~cm}^{-1}$ bands, a combination of $\left(\delta_{\mathrm{OH}}\right)+\left(v_{\mathrm{asOH}}\right)$ and a combination of $\left(v_{\mathrm{sOH}}\right)+\left(v_{\mathrm{asOH}}\right)$, respectively. Two types of differential procedures were performed to separate the contribution of the water sensitive bands from the entire spectrum: i.e., subtracting the spectrum of the test specimen conditioned at dryness of $0 \%$ relative humidity from that conditioned at a given relative humidity of $x \%$ (procedure $\mathrm{A}$ ) or the spectrum for $x \%$ from that for $(x+\Delta x) \%$ (procedure $\mathrm{B}$ ), both as functions of the given relative humidity of $x \%$. From the areas of the water sensitive bands thus separated, the moisture sorption isotherm could be composed in fairly good agreement with that obtained by a gravimetric method. The $6900 \mathrm{~cm}^{-1}$ band of bulk water as well as those in the differential spectra, were decomposed into three components of a Lorentzian function, sub-band I, I-II, and II in the order of descending wavenumber. They were attributed to three kinds of water species differing in the degree of hydrogen-bonding covering singly to doubly hydrogen-bonded water (ice-like water) species. It was found that the water species, which more strongly interact with each other, also more strongly interact with the water accessible sites of nylon 6 to form fewer number of layers of adsorption in the sense of B.E.T.'s multilayer adsorption or the core portion of water cluster in the sense of Hill's multimolecular adsorption. Semi-quantitative comparison was made between the characterization of the sorbed water by the B.E.T.'s multilayer adsorption and that by the present FT-IR spectroscopy.
\end{abstract}

KEY WORDS FT-IR Spectroscopy / Differential Spectrum / Sorbed Water

/ Nylon 6 / B.E.T. Multilayer Adsorption /

In a previous paper of this series, ${ }^{1}$ the interactions of water molecules with textile polymers were investigated for a series of natural polypeptide and synthetic polyamide fibers by analyzing their moisture sorption isotherms in terms of thermodynamic parameters of the sorption process as well as the parameters of Brunauer, Emmett, and Teller (B.E.T.)'s multilayer adsorption model. ${ }^{2}$ The investigation has further proceeded by means of broadline proton NMR to discuss the interaction in a molecular level.

From the temperature dependence of the moisture sorption isotherm, the thermody-

+ Presented in part at the 1986 Gorden Research Conference on Polymer Physics on July 15, 1986, Andover, New Hampshire, U.S.A., and in part at the 2nd International Polymer Conference on August 20, 1986, Tokyo, Japan.

${ }^{+\dagger}$ Present address: To-haku Junior High-school, To-haku-cho, Tottori 689-23, Japan.

t†† To whom correspondence should be addressed. 
namic parameters of the moisture sorption process were determined by an isosteric method $^{3}$ for a scoured wool and a nylon 6 fiber as a functions of relative humidity at $30^{\circ} \mathrm{C}$. The moisture sorption was of an exothermic process, associated with a decrease in entropy of the sorbed water relative to the water in liquid state. Namely, the differential heat of moisture sorption $Q_{\mathrm{L}}$ (internal energy) as well as the excess energy $T \Delta S$ (unavailable energy) of the sorbed water over bulk water, were found to be largest at dryness and still be finite, but not zero, even near saturation humidity. These facts revealed that the order of the sorbed water should be much higher, especially at dryness, than that in the liquid state, validating the application of the B.E.T.'s multilayer adsorption model (or equivalent Hill's water cluster formation model $)^{4}$ to these particular specimens of polypeptide and polyamide fibers.

The analysis of the sorption isotherm was performed for the series of polypeptide and polyamide fibers at $30^{\circ} \mathrm{C}$ in terms of the B.E.T.'s parameters: $v_{\mathrm{m}}$ (the maximum volume of monolayer-adsorbed water per gram of dry material), $C$ (the adsorptive energy factor), and $n_{\max }$ (the maximum number of adsorbed layers below which the calculated B.E.T. isotherm is closest but never exceeds the observed one). The molar concentration of the monolayer-adsorbed water (Langmuir's adsorption) normalized by the degree of noncrystallinity of the material, $\left[v_{\mathrm{m}} /\left(1-X_{\mathrm{x}}\right)\right]$, was found to increase gradually at first and then rapidly with an increase in the molar concentration of the [CONH] group in the backbone chain for the series of aliphatic polyamides including silk fibroin, but excluding the wool keratin and an aromatic polyamide fiber, Kevlar 29. A stoichiometry of polypeptide and polyamide interaction with water molecules was deduced such that the denser the $[\mathrm{CONH}]$ groups along the back-bone chain, the greater was the water adsorption per [CONH] group for the aliphatic polyamides, and that the primary moisture sorption was mostly governed by the [CONH] groups in the back-bone chain, rather than polar side-chain groups, for the silk fibroin and possibly vice versa for the wool keratin.

The $n_{\max }$ was found to be 6 for most specimens tested with a few exceptions, 7 for nylon 4 and 5 for nylon 6-12 and 12, and the other aromatic polyamide fiber, Teijin HM-50. The nature of sorbed water with $n=1$ (Langmuir's monolayer), with $n_{\max } \geqq n>1$ (B.E.T.'s multilayer), and with $n>n_{\max }$, was examined using the results obtained by the broadline proton NMR method. It was revealed that $n_{\max }$ corresponds to a transition at which the mobility of sorbed water increases up to a certain level of less interacted water, but not to a high level comparable to that of the bulk water. It is still necessary to make a more detailed analysis to distinguish the adsorbed water with $n=1$ from that with $n_{\max } \geqq n>1$.

In this paper, therefore, the interaction of moisture with nylon 6 is investigated using a Fourier transform infrared (FT-IR) spectroscopy over a near-infrared range of 4500 $8000 \mathrm{~cm}^{-1}$ covering the first over-tones of the $\mathrm{C}-\mathrm{H}$ and $\mathrm{N}-\mathrm{H}$ stretching bands as well as the water sensitive 5100 and $6900 \mathrm{~cm}^{-1}$ bands, a combination of the $\mathrm{O}-\mathrm{H}$ bending $\left(\delta_{\mathrm{OH}}\right)+$ the antisymmetric $\mathrm{O}-\mathrm{H}$ stretching $\left(v_{\mathrm{asOH}}\right)$ and a combination of the antisymmetric $\mathrm{O}-\mathrm{H}$ stretching + the symmetric $\mathrm{O}-\mathrm{H}$ stretching $\left(v_{\mathrm{sOH}}\right)$, respectively. The differential spectrum of nylon 6 between the specimens conditioned at different relative humidities, $(x+\Delta x) \%$ and $x \%$, represents the state of the water bands at $x \%$ relative humidity. The differential spectrum thus obtained, especially for the $6900 \mathrm{~cm}^{-1}$ band, may be used to quantify the moisture sorption from the band area and specify the nature of the sorbed water from the band shift relative to that of the bulk water. 


\section{TEST SPECIMENS AND EXPERIMENTAL PROCEDURE}

An isotropic film of nylon 6 was cast by a Tdie melt-extruder with a thickness of about $200 \mu \mathrm{m}$. The film was cut into test specimens $50 \mathrm{~mm}$ long and $25 \mathrm{~mm}$ wide. The specimens were washed in a Soxhlet extructor with carbon tetrachloride, leached in boiling water for a few hours to remove origomeric components, if any, air-dried, and further dried in a vacuum oven for two days at $90^{\circ} \mathrm{C}$ to prepare bone-dried specimens. They were used for the measurement of the moisture sorption isotherm by a gravimetric method using a weighing bottle. This bottle containing ten pieces of the bone-dried specimen was kept in a desiccator, and the specimen was conditioned at a given temperature and a given vapour pressure adjusted by an aqueous solution of sulfuric acid at a given concentration. Usually, it takes as long as at least three weeks until a sorption equilibrium has been attained, especially when the equilibrium value approaches saturation.

In practice, a set of twelve desiccators differing in the concentration of the sulfuric acid contained and, consequently, covering a whole range of relative humidity from 0 to $100 \%$, was used as to determine at once the sorption isotherm over the whole range. The desiccators were stored in a huge thermostatted air-bath controlled at $30 \pm 1{ }^{\circ} \mathrm{C}$ by forced air-flow. Moisture up-take at equilibrium in the sorption process was represented by $\%$-regain defined as

$\%$-regain

$$
=\frac{\text { mass of moisture up-take }}{\text { unit mass of bone-dried specimen }} \times 100
$$

The plot of open circles in Figure 1 is the moisture sorption isotherm obtained, displaying a typical sigmoid shape characteristic of hydrophilic polymers.
Brunauer, Emmett, and Teller ${ }^{2}$ extended the Langmuir's monolayer adsorption mechanism $^{5}$ to multilayer adsorption and developed a multilayer adsorption isotherm: i.e., a sort of kinetic theory equating the rate of evaporation of moisture from surface area $A_{i+1}$ covered by $(i+1)$ layers to that of condensation of moisture on surface area $A_{i}$ covered by $i$ layers and resulting in the following isotherm for unrestricted adsorption of infinite layers:

$$
v=\frac{v_{\mathrm{m}} C p}{\left(p_{\mathrm{s}}-p\right)\left[1+(C-1) p / p_{\mathrm{s}}\right]}
$$

where

$$
\begin{gathered}
v=v_{0} \sum_{0}^{\infty} i A_{i} \\
v_{\mathrm{m}}=v_{0} \sum_{0}^{\infty} A_{i} \\
C=C_{0} \exp \left[\left(U_{1}-U_{\mathrm{L}}\right) / R T\right]
\end{gathered}
$$

Here, $v_{0}$ is the volume of moisture adsorbed per unit area of the monolayer, and, consequently, $v$ and $v_{\mathrm{m}}$ are the total volume of multilayer-adsorbed moisture and maximum volume of monolayer-adsorbed moisture, respectively, both per unit mass of dry material. $C$ is the adsorptive energy factor defined by eq 5 in which $C_{0}\left(=a_{1} / b_{1} \cdot b_{i} / a_{i}\right)$ is assumed to be a constant near unity, irrespective of $i$, and $U_{1}$ and $U_{\mathrm{L}}$ are binding energy between the adsorbent and adsorbate and that between the adsorbates (heat of liquefaction), respectively.

If adsorption is restricted to a finite number of molecular layers, the following isotherm may be obtained:

$$
v=\frac{v_{\mathrm{m}} C x}{(1-x)} \frac{1-(n+1) x^{n}+n x^{n+1}}{1+(C-1) x-C x^{n+1}}
$$

where $x\left(=p / p_{\mathrm{s}}\right)$ is the relative humidity, and $n$ represents the maximum number of adsorbed molecular layers. It is noted that eq 6 reduces to Langmuir's equation for monolayer adsorption when $n$ is reduced to unity. 


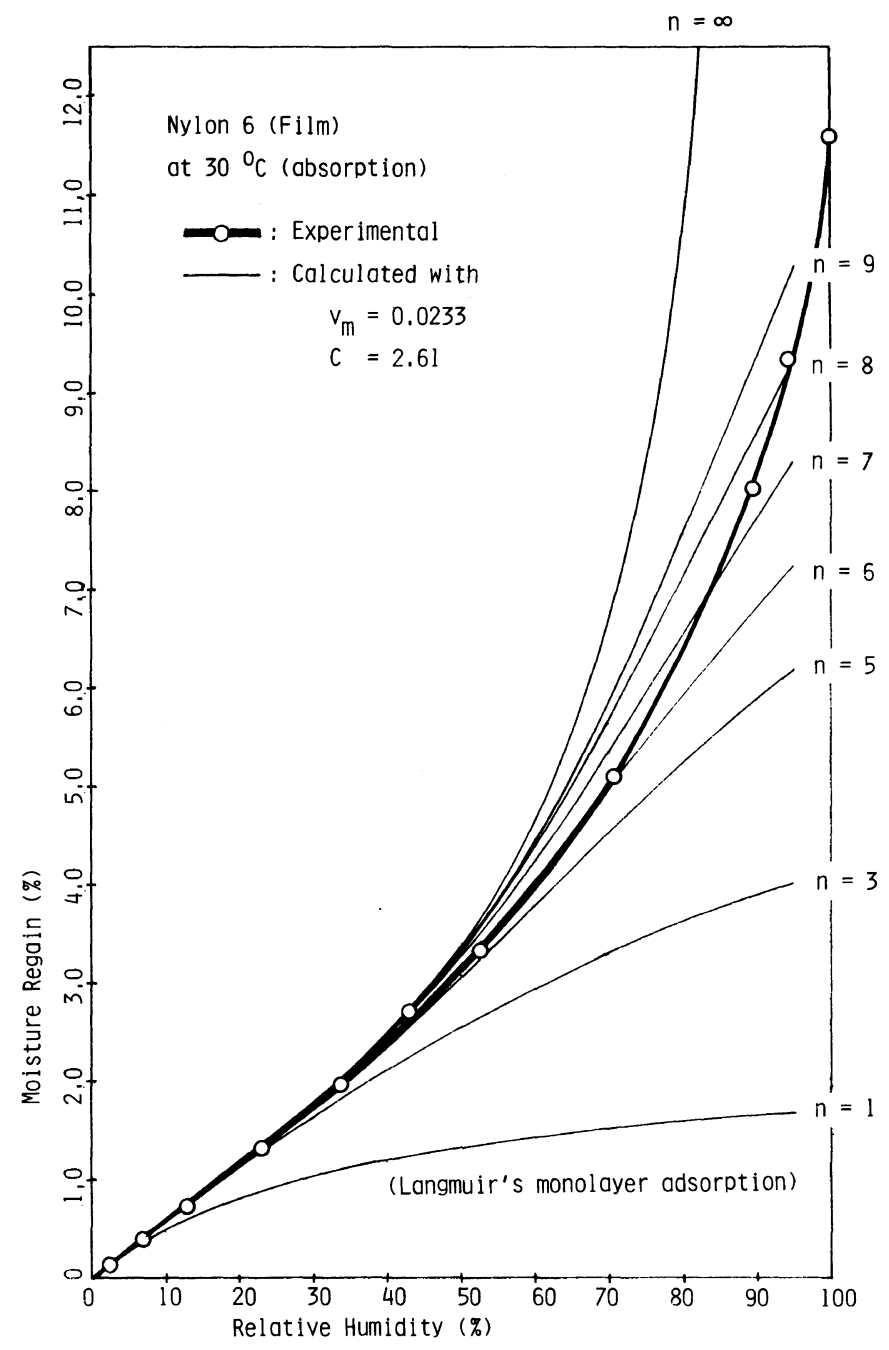

Figure 1. Comparison of moisture sorption isotherms of nylon 6 specimen observed at $30^{\circ} \mathrm{C}$ by a gravimetric method with those calculated from B.E.T.'s multilayer adsorption model by fixing the B.E.T.'s parameters, $v_{\mathrm{m}}$ and $C$, at 0.0233 and 2.61 , respectively, but varying the number of layers $n$ from unity to infinity.

Equation 2 is rewritten as

$$
\frac{x}{v(1-x)}=\frac{1}{v_{\mathrm{m}} C}+\frac{(C-1)}{v_{\mathrm{m}} C} x
$$

and from the B.E.T. linear plot of $x /[v(1-x)]$ vs. $x, v_{\mathrm{m}}$ and $C$ can be determined from the slope and intercept, respectively. The linear relationship given by eq 7 is usually found for the sorption isotherm data of hydrophilic textile polymers in a range of relative humidity less than $\mathrm{ca} .40 \%$, as demonstrated in Figure 2, and the values of $v_{\mathrm{m}}$ and $C$ were obtained as 0.0233 and 2.61, respectively, for this particular case.

In Figure 1 the experimental moisture sorption isotherm of the nylon 6 film is compared with those calculated from eq 2 and 6 for various numbers of adsorbed layers with the fixed values of $v_{\mathrm{m}}=0.0233$ and $C=2.61$. The calculated curve for $n=1$ fits the experimental 


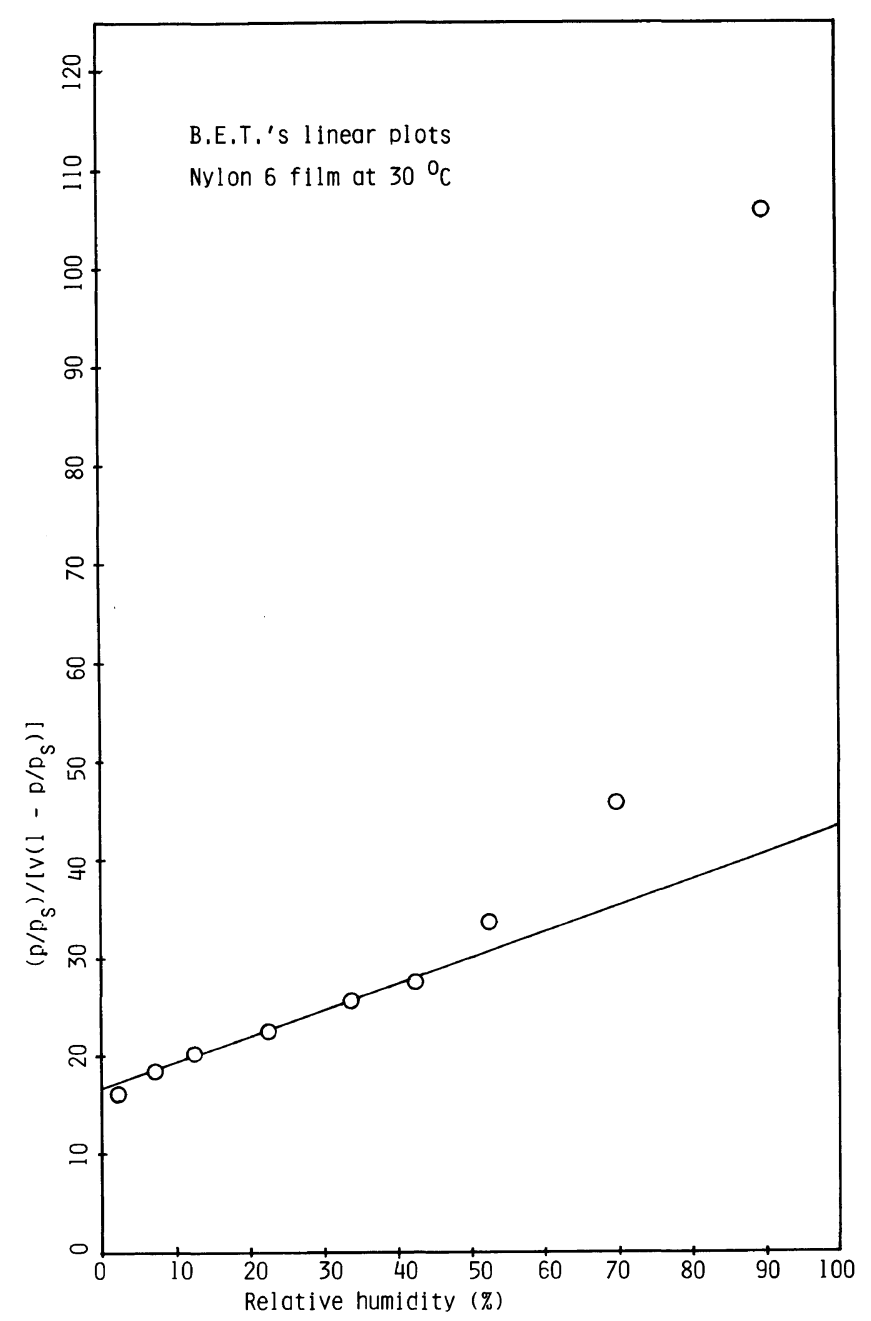

Figure 2. Linear plots of $\left(p / p_{\mathrm{s}}\right) / v\left[1-\left(p / p_{\mathrm{s}}\right)\right]$ against $\left(p / p_{\mathrm{s}}\right)$ to determine the B.E.T.'s parameters, $v_{\mathrm{m}}$ and $C$, from sorption isotherm data for the nylon 6 specimen at $30^{\circ} \mathrm{C}$.

data only in a very low humidity range of less than a few $\%$, whereas the calculated curve for $n=\infty$ fits the experimental data in a humidity range up to about $40 \%$ beyond which it increases much more rapidly than the experimental results. Between the two extremes of $n=1$ and $\infty$, there is a calculated curve corresponding to a maximum number of $n$, designated hereafter as $n_{\text {max }}$, below which the calculated curve is closest but never exceeds the experimental result; i.e., $n_{\max }=6$ for this particular case of nylon 6 film. We can define three kinds of moisture regain at a given relative humidity: with $n=1$ due to Langmuir's monolayer adsorption, with $n_{\max } \geqq$ $n>1$ due to the B.E.T.'s multilayer adsorption, and with $n>n_{\max }$ due to another type of sorption mechanism.

In Table I are listed the bulk density $\rho$ and the X-ray crystallinity $X_{x}$ as well as the moisture sorption characteristics of the nylon 6 film at $30^{\circ} \mathrm{C}$ in terms of the values of the B.E.T.'s parameters and the three kinds of moisture regain at $95 \%$ relative humidity. The values of 
Table I. Moisture sorption characteristics of nylon 6 film at $30^{\circ} \mathrm{C}$ in terms of the B.E.T. parameters and three kinds of moisture regain

\begin{tabular}{|c|c|c|c|c|c|c|c|c|c|}
\hline \multirow{3}{*}{ Specification } & \multirow{3}{*}{$\frac{\rho^{\mathrm{a}}}{\mathrm{g} \mathrm{cc}^{-1}}$} & \multirow{3}{*}{$\frac{X_{\mathrm{x}}^{\mathrm{b}}}{\%}$} & \multirow{3}{*}{$v_{\mathrm{m}}$} & \multirow{3}{*}{$C$} & \multirow{3}{*}{$n_{\max } \mathrm{c}$} & \multicolumn{3}{|c|}{ Moisture regain at $95 \% \mathrm{RH}^{\mathrm{d}}$} & \multirow{3}{*}{$\begin{array}{l}\text { Moisture regain } \\
\text { at } 65 \% \mathrm{RH} \\
\text { in bulk } \\
\frac{\%}{\%}\end{array}$} \\
\hline & & & & & & $n=1$ & $n_{\max } \geqq n>1$ & $n>n_{\max }$ & \\
\hline & & & & & & $\%$ & $\%$ & $\%$ & \\
\hline Nylon 6 film & $1.128_{0}$ & 32.0 & 0.0233 & 2.61 & 6 & 1.70 & 5.55 & 2.50 & 4.55 \\
\hline
\end{tabular}

a Bulk density determined by a density-gradient-column with toluene $/ \mathrm{CCl}_{4}$ at $30.0^{\circ} \mathrm{C}$.

b Degree of crystallinity determined from X-ray diffraction.

c Maximum number of adsorbed layers below which the calculated isotherm never exceeds that observed.

d $\mathrm{RH}$, relative humidity.
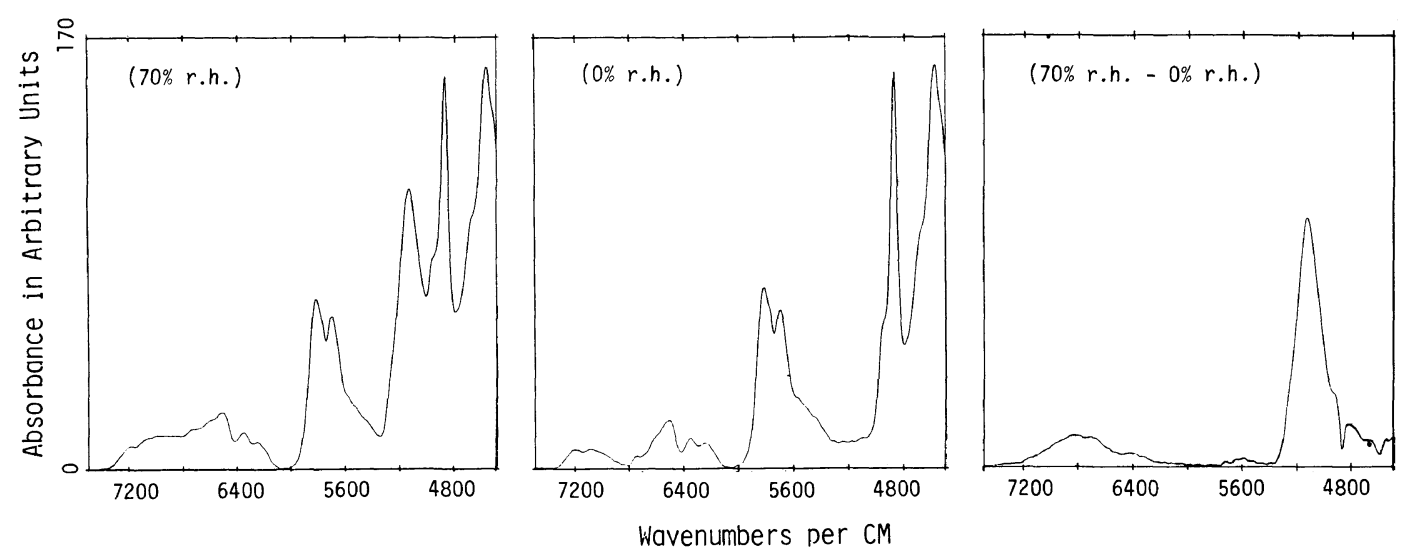

Figure 3. Comparison of near-infrared spectra of nylon 6 at 0 and $70 \%$ relative humidities at $30^{\circ} \mathrm{C}$ with differential spectrum between them, demonstrating complete elimination of the $\left(2 v_{\mathrm{CH}}\right)$ doublet taken as the internal standard.

$v_{\mathrm{m}}$ and $C$ are reasonable in comparison with literature ones for several kinds of natural polypeptide and synthetic polyamide fibers. ${ }^{6-12}$

Measurement of the infrared spectrum of the nylon 6 specimen was performed by a transmission technique using an FT-IR spectrometer, Digilab Model FTS 15C, over a nearinfrared range from 4500 to $8000 \mathrm{~cm}^{-1}$ as a function of relative humidity at which the film specimen had been conditioned at $30^{\circ} \mathrm{C}$. The specimen exhibited the first over-tone of the $\mathrm{N}-\mathrm{H}$ and $\mathrm{C}-\mathrm{H}$ stretching bands as well as other minor bands of aliphatic polyamide, superposed by two water sensitive bands ap- pearing at around 5100 and $6900 \mathrm{~cm}^{-1} \cdot{ }^{13,14}$

The reason why the absorption in the nearinfrared range was measured rather than the mid infrared range, was due not only to some improvement in resolution power of the FT-IR measurement, but mostly due to the following reasons: 1) possibility of using an extremely thick specimen, as thick as $2 \mathrm{~mm}$ (in practice ten piles of the test specimen of $200 \mu \mathrm{m}$ in thickness), which is stable enough in preconditioned moisture up-take even during the FT-IR measurement for several minutes without any sealing of the specimen against the atmosphere; 2) the assignments of water sensitive bands are rather well-established for the 
near-infrared range than for the mid infrared range, as reviewed by Kuntz and Kauzman ${ }^{15}$ and will be discussed in detail later.

In order to separate the water sensitive bands from the entire near-infrared spectrum, two types of differential procedures were conducted by taking the first over-tone of the $\mathrm{C}-\mathrm{H}$ stretching modes, which appeared as a doublet at around $5800 \mathrm{~cm}^{-1}$ due to $\left(v_{\mathrm{sCH}}\right)$ and $\left(v_{\mathrm{asCH}}\right)$, as the internal standard: subtracting the spectrum at $0 \%$ humidity from that at $x \%$ humidity (procedure $\mathrm{A}$ ) or the spectrum at $x \%$ humidity from that at $(x+\Delta x) \%$ humidity (procedure B). Figure 3 shows an example of the differential spectrum obtained by procedure $\mathrm{A}$ between the original spectra at 70 and $0 \%$ relative humidities, demonstrating not only the separation of the two water sensitive bands centered at around 5100 and $6900 \mathrm{~cm}^{-1}$, respectively, but also elimination of the doublet of the $\mathrm{C}-\mathrm{H}$ stretching modes taken as the internal standard. When comparing the differential spectrum with the two original spectra of nylon 6 at 70 and $0 \%$ relative humidities, the elimination must be satisfactory.

\section{EXPERIMENTAL RESULTS AND DISCUSSION}

The N-H stretching band of polyamides and polyurethanes has been employed by many authors to estimate the thermodynamic parameters associated with the hydrogen-bond formation with carbonyl group. ${ }^{16-27}$ The amino group must be one of the most water accessible sites, and the study on moisture dependence of the $\mathrm{N}-\mathrm{H}$ stretching mode may be an approach to investigate the interactions of the sorbed water with polyamides and polypeptides, as carried out by Ellis and Bath as early as in $1938 .^{28}$

The $\mathrm{N}-\mathrm{H}$ stretching vibration is an isolated mode and not a conformational sensitive mode. ${ }^{29,30}$ Instead, the broadness of the hydrogen-bonded $\mathrm{N}-\mathrm{H}$ band reflects a distribution of hydrogen-bonded $\mathrm{N}-\mathrm{H}$ groups of varying strengths. Actually, the $\mathrm{N}-\mathrm{H}$ stretching band is composed of two major parts due to 'free' and 'hydrogen-bonded' $\mathrm{N}-\mathrm{H}$ groups both distributed rather widely at 3440 and $3310 \mathrm{~cm}^{-1}$, respectively. Each part has been measured by using an average absorption coefficient to relate its band area to concentration of the corresponding amino groups. Very recently, however, the absorption coefficient has been revealed not only to be temperature dependent, but strongly frequency dependent by Painter et al. ${ }^{31}$ They intend to invalidate the concept of average absorption coefficient upon which most previous studies including the estimation of the thermodynamic parameters of hydrogen-bond formation are based. The situation must be more problematic when taking into account the additional complication of crystallinity for semicrystalline materials.

In this study, therefore, the $\mathrm{O}-\mathrm{H}$ stretching mode of sorbed water molecule, rather than the $\mathrm{N}-\mathrm{H}$ stretching mode of the amino group, was used to investigate the interaction between the water molecule and adsorbent and the water molecules themselves and, consequently, the state of the sorbed water in the nylon 6 specimen, since the $\mathrm{O}-\mathrm{H}$ stretching frequencies and intensities are quite sensitive to the hydrogen-bond formation.

It has been well established that the water molecule in gas phase has three normal modes assigned to $\left(v_{\mathrm{asOH}}\right),\left(v_{\mathrm{sOH}}\right)$, and $\left(\delta_{\mathrm{OH}}\right)$ with centered wavenumbers of 3755,3657 , and $1595 \mathrm{~cm}^{-1}$, respectively. In the liquid state, however, the assignments are still much disputed, as discussed by Eisenberg and Kauzmann, ${ }^{32}$ Walrafen, ${ }^{33}$ and Murphy and Bernstein $^{34}$ primarily based on Raman spectroscopy. The $\mathrm{O}-\mathrm{H}$ stretching region contains at least two broad bands centered at 3490 and $3280 \mathrm{~cm}^{-1}$. The $\mathrm{O}-\mathrm{H}$ bending is relatively little shifted at $1645 \mathrm{~cm}^{-1}$ in contrast to the considerable shift of the $\mathrm{O}-\mathrm{H}$ stretching to the lower wavenumber side.

In addition to these fundamental bands, combination and overtone bands extend 
throughout the near-infrared and into the visible region of the spectrum. The bands at 5100 and $6900 \mathrm{~cm}^{-1}$ have been relatively well studied to assign them to the combination of $\left(v_{\mathrm{asOH}}\right)+\left(\delta_{\mathrm{OH}}\right)$ and also the combination of $\left(v_{\text {asOH }}\right)+\left(v_{\text {sOH }}\right)$, respectively, ${ }^{13,14,35-37}$ though there have been some oppositions to assign the $6900 \mathrm{~cm}^{-1}$ bands to the first overtone of the $\mathrm{O}-\mathrm{H}$ stretching $\left(2 v_{\mathrm{OH}}\right)^{33,37,38}$ or to a combination of the first overtone of the $\mathrm{O}-\mathrm{H}$ bending $\left(2 \delta_{\mathrm{OH}}\right)$ and the $\mathrm{O}-\mathrm{H}$ stretching $\left(v_{\mathrm{OH}}\right) \cdot{ }^{39}$ This is one of the reasons why we adopted the near-infrared water sensitive bands at 5100 and $6900 \mathrm{~cm}^{-1}$.

Figure 4 shows the change in near-infrared spectrum of the nylon 6 specimen over a range of wave numbers from 4500 to $8000 \mathrm{~cm}^{-1}$ with the relative humidity at which the specimen has been conditioned at $30^{\circ} \mathrm{C}$. The nearinfrared spectrum of bulk water is added, as a reference, at the right botton corner in the figure. Two water sensitive bands centered at 5100 and $6900 \mathrm{~cm}^{-1}$ grow with an increase in relative humidity. Taking the first overtone of the $\mathrm{C}-\mathrm{H}$ stretching modes, appearing as a doublet at around $5800 \mathrm{~cm}^{-1}$, as the internal standard, two types of differential procedures $\mathrm{A}$ and $\mathrm{B}$, were performed so as to completely eliminate the $\mathrm{C}-\mathrm{H}$ stretching doublet band. The differential spectrum thus separated by the procedure $A$ for the $5100 \mathrm{~cm}^{-1}$ band and those by the procedures $A$ and $B$ for the $6900 \mathrm{~cm}^{-1}$ band, are illustrated in Figures 5-7, respectively, all as functions of relative humidity of $x \%$ at $30^{\circ} \mathrm{C}$.

The growth of the 5100 and $6900 \mathrm{~cm}^{-1}$ bands with sorption of moisture can be clearly seen in the figures, particularly in Figures 5 and 6 obtained by procedure A. From the area of the separated bands, one can compose the moisture sorption isotherm, as shown in Figure 8 , on the basis that the area is proportional to the concentration of sorbed water. Although no correction due to the frequency dependence of the absorption coefficient ${ }^{31}$ has been performed, fairly good agreement be- tween the isotherms obtained by the gravimetric and the infrared methods was achieved with the exception of some discrepancy at intermediate relative humidities.

As expected from the normal modes of water molecules in the gas and liquid phases, the $\left(v_{\mathrm{sOH}}\right)$ and the $\left(v_{\mathrm{asOH}}\right)$ modes shift to the lower wavenumber side, while the $\left(\delta_{\mathrm{OH}}\right)$ mode shifts to the higher wavenumber side, with an increase in the hydrogen bonding force. This suggests that the $5100 \mathrm{~cm}^{-1}$ band, the combination band of $\left(\delta_{\mathrm{OH}}\right)+\left(v_{\mathrm{asOH}}\right)$, must be too complicated to discuss the nature of the sorbed water from the band shift, and the $6900 \mathrm{~cm}^{-1}$ band will be mostly used for further discussion on the characterization of the sorbed water. As shown in Figures 6 and 7, the $6900 \mathrm{~cm}^{-1}$ band of the sorbed water, after subtraction, is considerably broad and asymmetric, revealing a shoulder at around $6400 \mathrm{~cm}^{-1}$ as well as a double or triple peak. It is uncertain, at present, whether the double or triple peak has been correctly separated or incorrectly resulted from insufficient subtraction of the first overtone of the $\mathrm{N}-\mathrm{H}$ stretching mode which appears at around $6900 \mathrm{~cm}^{-1}$ and is also affected by the sorbed water.

Neglecting the effect of the $\mathrm{N}-\mathrm{H}$ stretching mode, if any, smoothing the double or triple peak into a single peak, one can decompose the differential spectrum of the $6900 \mathrm{~cm}^{-1}$ band into two components, sub-band $\mathrm{I}$ at higher wavenumber side and sub-band II at lower wavenumber side, by a nonlinear least square method assuming each component to be represented by a given symmetric function, such as Lorentzian function. This was performed, as demonstrated in Figure 9, for example, for the $6900 \mathrm{~cm}^{-1}$ band of bulk water as well as for those of the differential spectra separated by procedures $\mathrm{A}$ and $\mathrm{B}$. This reveals that decomposition can be successful only by a modified Lorentzian function, Pearson's type VII function, but never by the Lorentzian function. The Pearson's type VII function has an additional parameter of $m$ and is given by 
FT-IR Spectroscopy of Sorbed Water by Nylon 6

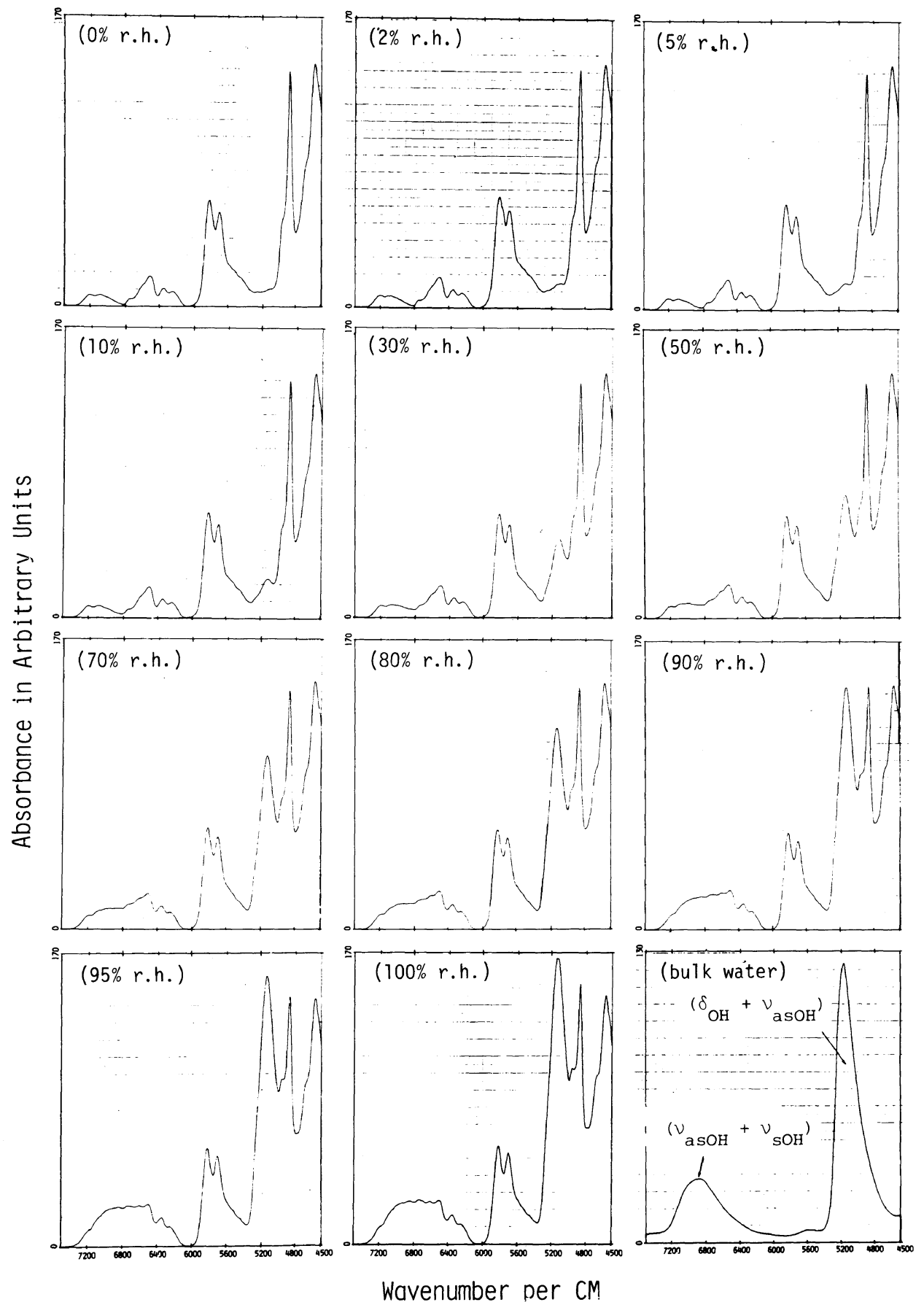

Figure 4. Change in near-infrared spectrum of nylon 6 specimen over a range of wavenumbers from 4500 to $7500 \mathrm{~cm}^{-1}$ with relative humidity at which the specimen has been conditioned at $30^{\circ} \mathrm{C}$. The spectrum of bulk water is also added at the right bottom corner. 


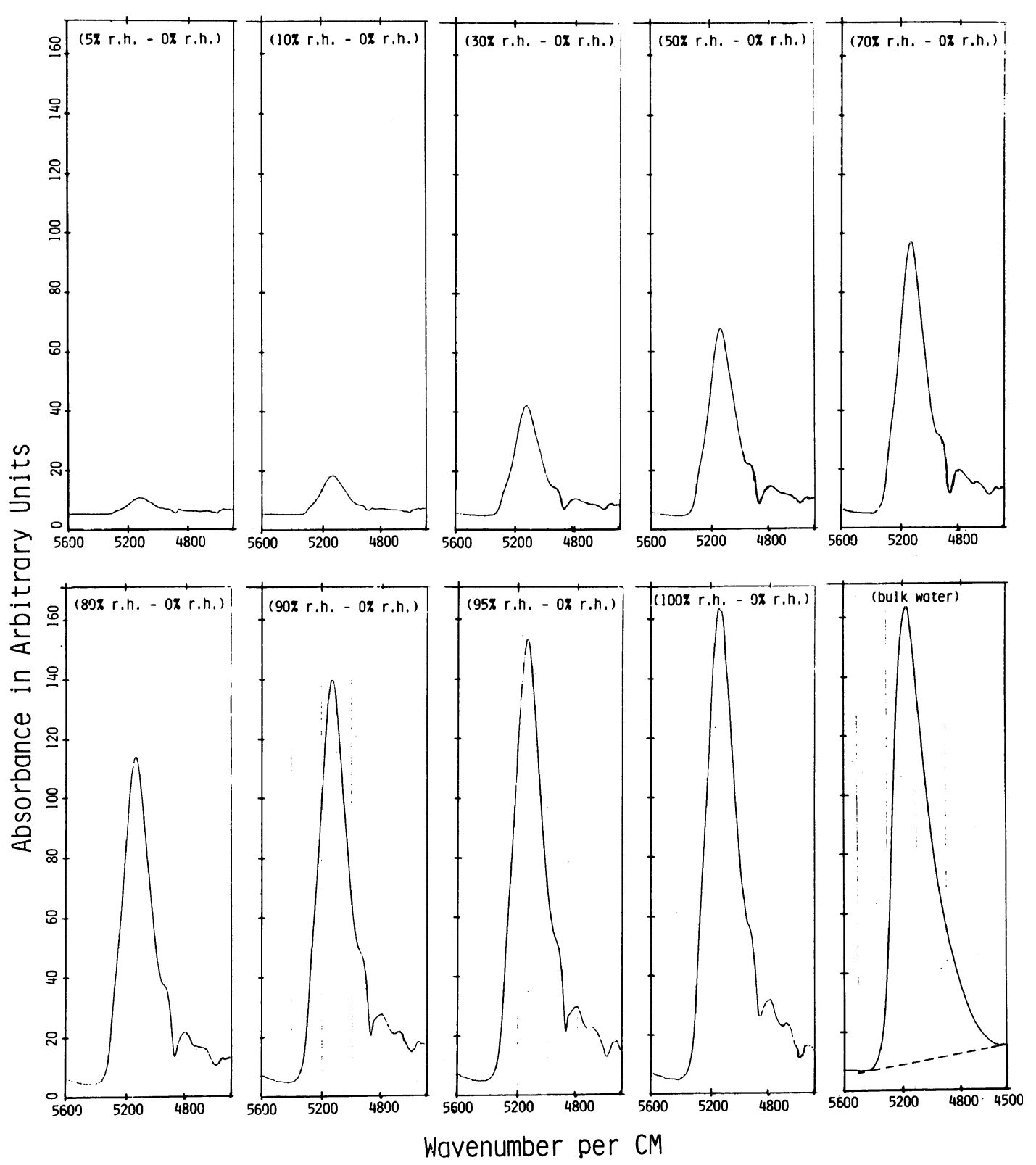

Figure 5. Change in the differential spectrum for $5100 \mathrm{~cm}^{-1}$ water sensitive band, separated by the procedure A, with the relative humidity of $x \%$. The $5100 \mathrm{~cm}^{-1}$ band for bulk water is also added at the right bottom corner.

$h=H /\left\{1+\left(\frac{w-w_{0}}{W}\right)^{2}\left(2^{1 / m}-1\right)\right\}^{m}$ where $H$ is peak height, $w_{0}$ is peak wavenumber, $W$ is half-width at half-intensity of the sub-band, and $m$ is a positive value reducing 
FT-IR Spectroscopy of Sorbed Water by Nylon 6
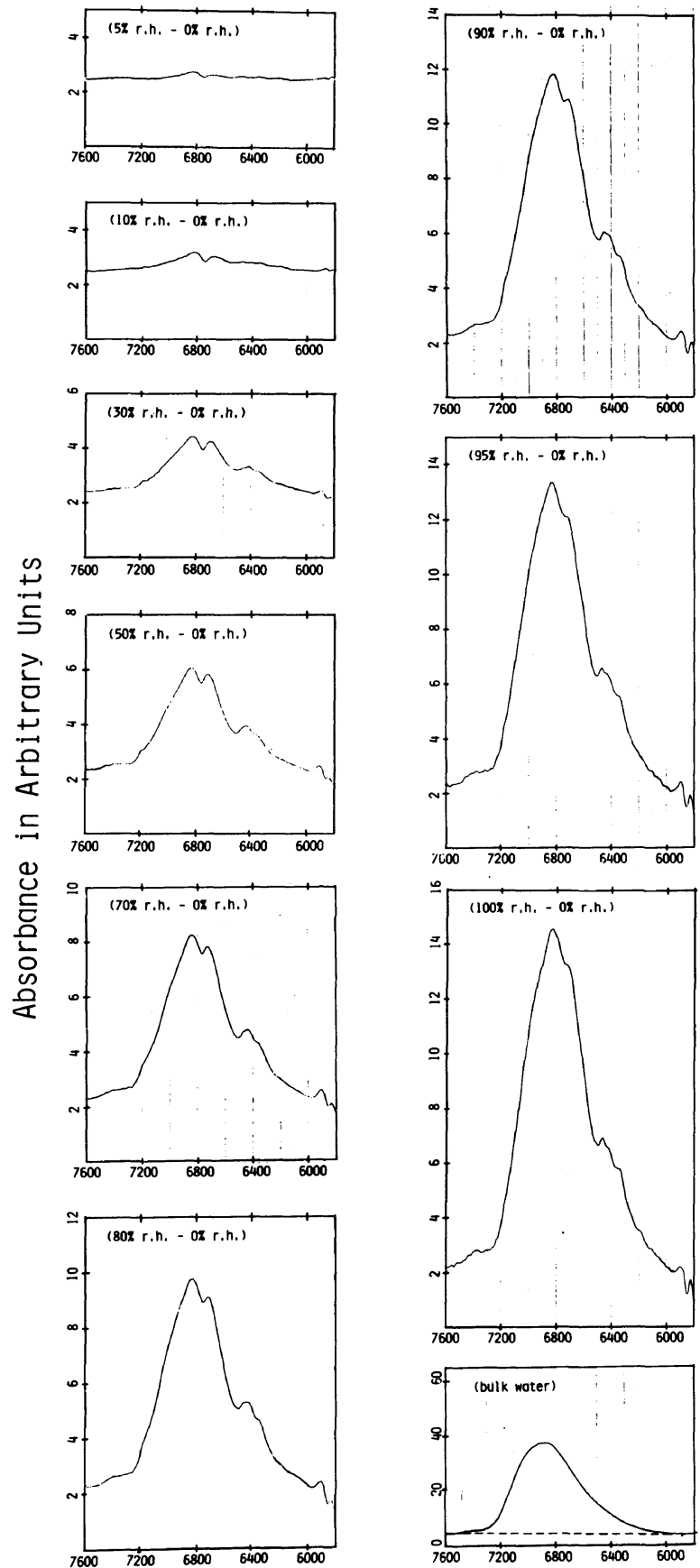

Wavenumber per $\mathrm{CM}$

Figure 6. Change in the differential spectrum for $6900 \mathrm{~cm}^{-1}$ water sensitive band, separated by procedure A, with the relative humidity of $x \%$. The $6900 \mathrm{~cm}^{-1}$ band for bulk water is also added at the right bottom corner. 

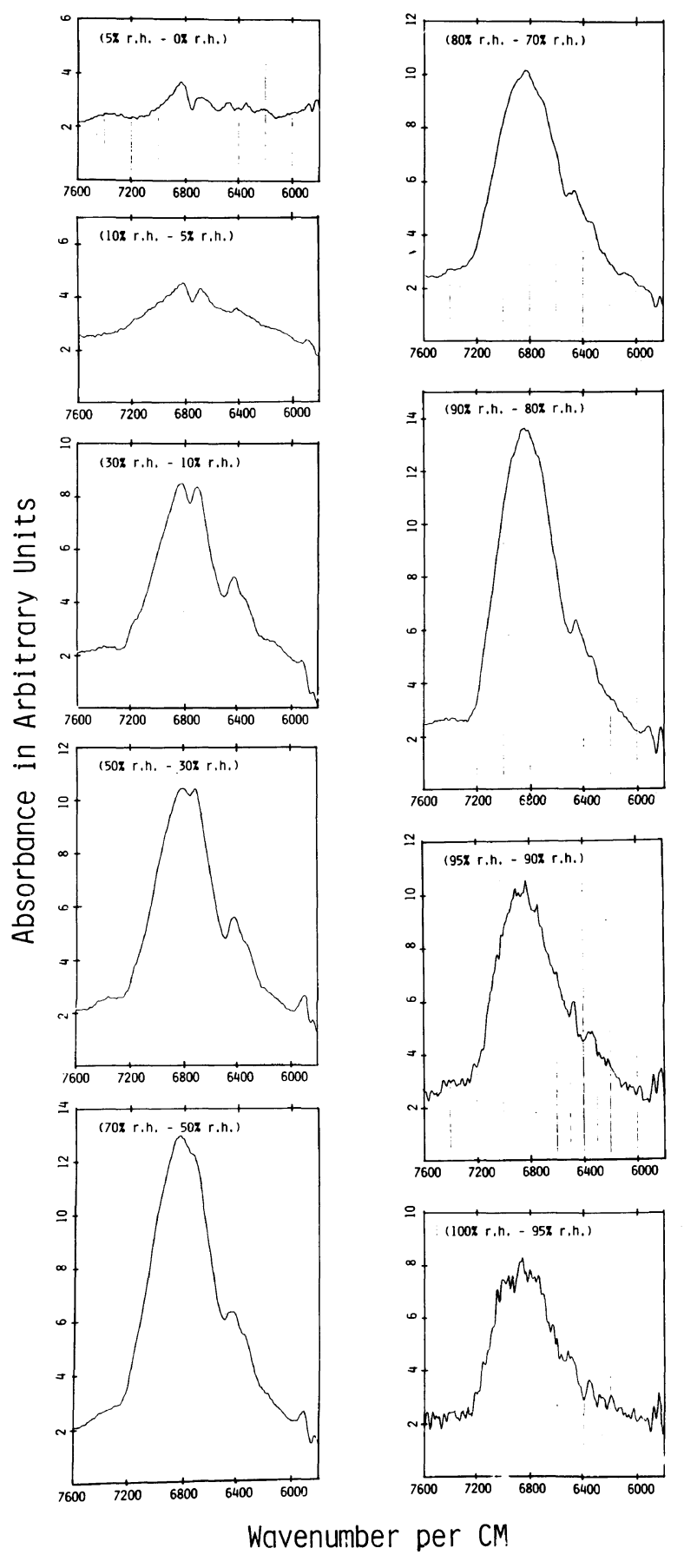

Figure 7. Change in the differential spectrum for $6900 \mathrm{~cm}^{-1}$ water sensitive band, separated by procedure $\mathrm{B}$, with the relative humidity of $x \%$. 


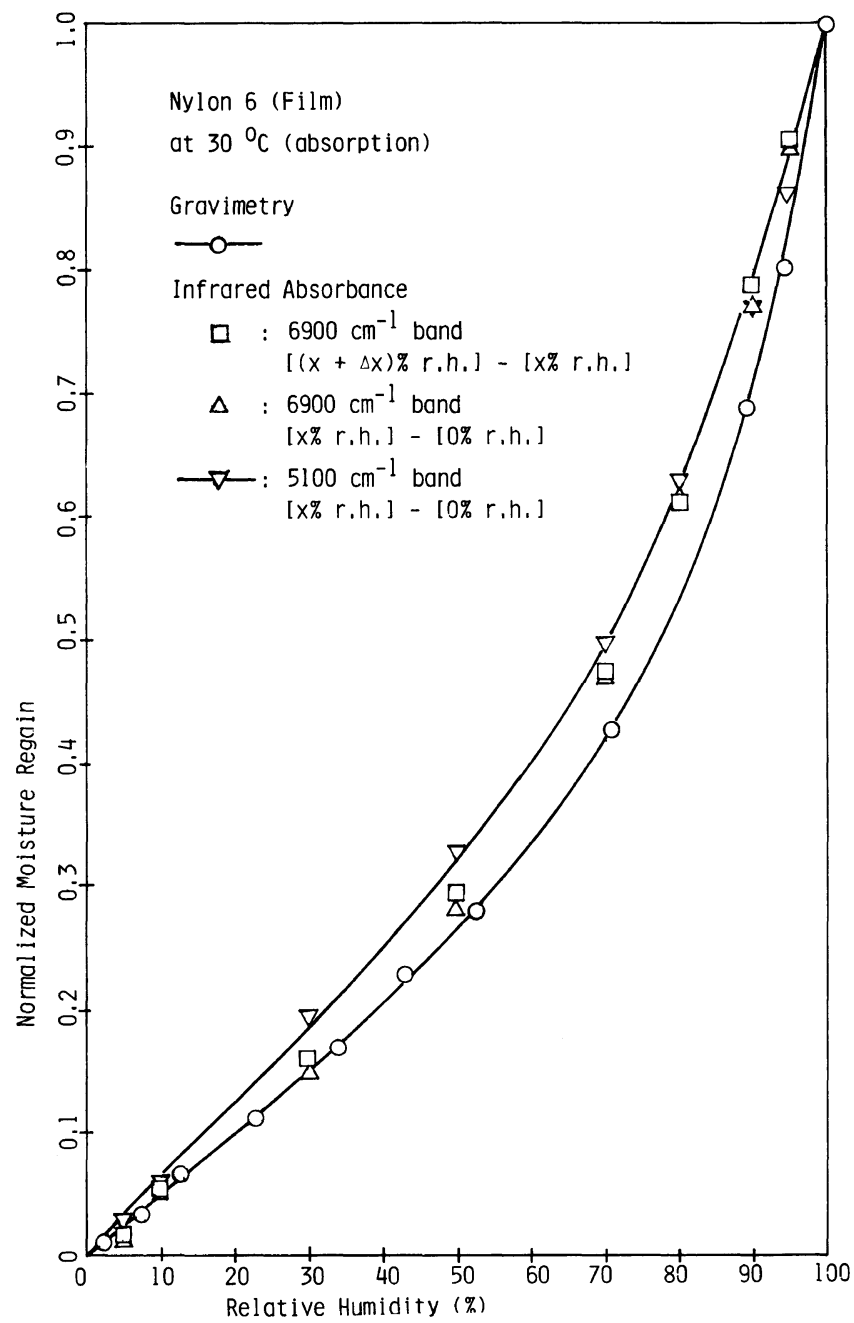

Figure 8. Comparison of moisture sorption isotherm, observed by the gravimetric method and normalized by its saturation regain, with those composed from the areas of differential spectra for the 5100 and $6900 \mathrm{~cm}^{-1}$ water sensitive bands.

the Lorentzian function when it is unity. Results of the decomposition of the $6900 \mathrm{~cm}^{-1}$ band into the two components are listed in Table II in terms of the values of peak height, peak wavenumber, half-width, and relative peak area for all the differential spectra separated by procedures $A$ and $B$ as well as for the bulk water. The value of $m$ was found to be much larger than unity for the sub-band I and less than unity for the sub-band II, in general, but to vary randomly without any systema- ticity with a referenced relative humidity of $x \%$.

Postulating the double or triple peak to be intrinsic one correctly separated by the differential procedures, it is possible to decompose the $6900 \mathrm{~cm}^{-1}$ band into at least three components, sub-band I, sub-band I-II, and subband II in the order of descending wavenumber, by the nonlinear least square method assuming each component to be given by a Lorentzian function. In Figure 10 are illus- 


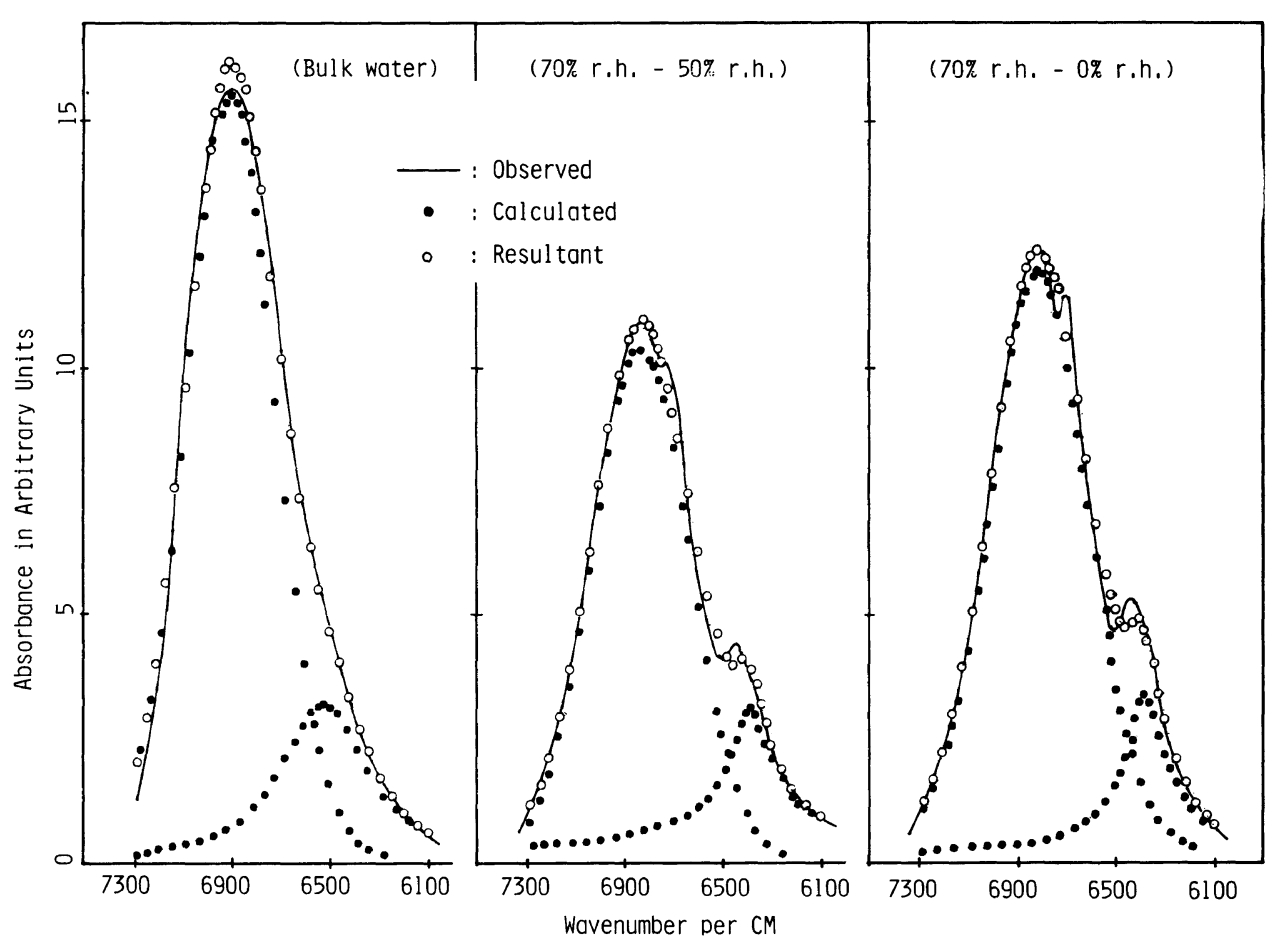

Figure 9. Decomposition of the $6900 \mathrm{~cm}^{-1}$ bands for the bulk water as well as for the differential spectra separated by procedures B (middle) and A (right) into two components, sub-band I and II in the order of descending wavenumber, by a nonlinear least square method assuming each component to be given by Pearson's type VII function.

trated some results of the decomposition, for example, for the bulk water as well as for the differential spectra separated by procedure B. The final results of the three component decomposition are listed in Table III in terms of the values of the Lorentzian function parameters.

As far as the decomposition procedure is concerned, it must be acceptable, at least phenomenologically, to take the number of the components as small as possible with a unified function to represent each component. In this sense, the two component decomposition with Pearson's type VII function has a serious problem about the random variation of $m$, while the three component decomposition with the Lorentzian function has an inferiority having one more component than the two component decomposition unless the one more component is essentially necessitated. Actually, McCabe et al. ${ }^{14}$ studied the temperature dependence of the $6900 \mathrm{~cm}^{-1}$ band in bulk water and decomposed it into two major components attributed to singly hydrogen-bonded and ice-like (doubly hydrogen-bonded) water species, though admitting an intermediate temperature independent component between the two major components.

Murphy and Bernstein ${ }^{34}$ studied the stretching (fundamental) band of bulk water by Raman spectroscopy and assigned it to five $\mathrm{O}-\mathrm{H}$ stretching modes on the basis of a simple model for bulk water involving two molecular species having either four or three hydrogen bonds, i.e., fully bonded tetracoordinated species and the species of tricoordinated type which has a free $\mathrm{OH}$. Walrafen ${ }^{33}$ referred the $6900 \mathrm{~cm}^{-1}$ band of bulk water to the overtones 
FT-IR Spectroscopy of Sorbed Water by Nylon 6

Table II. Decomposition of $6900 \mathrm{~cm}^{-1}$ band into two components of Pearson's type VII function

\begin{tabular}{|c|c|c|c|c|c|c|c|c|c|c|}
\hline \multirow[t]{2}{*}{ Specimen code } & \multicolumn{3}{|c|}{$\begin{array}{l}\text { Peak height } \\
\text { (relative value) }\end{array}$} & \multicolumn{3}{|c|}{$\frac{\text { Peak wavenumber }}{\mathrm{cm}^{-1}}$} & \multicolumn{2}{|c|}{$\frac{\text { Half-width }}{\mathrm{cm}^{-1}}$} & \multicolumn{2}{|c|}{$\begin{array}{c}\text { Peak area } \\
\text { (relative value) }\end{array}$} \\
\hline & $H_{1}$ & $H_{\mathrm{il}}$ & $H_{\mathrm{I}} / H_{\mathrm{Il}}$ & $w_{\mathrm{ol}}$ & $w_{\mathrm{oll}}$ & $w_{\text {ol }} / w_{\text {oll }}$ & $W_{1}$ & $W_{\mathrm{II}}$ & $H_{\mathrm{I}} \times W_{\mathrm{I}}$ & $H_{11} \times W_{11}$ \\
\hline$(100 \% \mathrm{RH}-0 \% \mathrm{RH})$ & 100 & 26.2 & 3.82 & 6836 & 6395 & 1.069 & 225 & 171 & 2250 & 448 \\
\hline$(95 \% \mathrm{RH}-0 \% \mathrm{RH})$ & 88.6 & 24.2 & 3.66 & 6829 & 6408 & 1.066 & 213 & 139 & 1890 & 336 \\
\hline$(90 \% \mathrm{RH}-0 \% \mathrm{RH})$ & 74.6 & 25.6 & 2.91 & 6821 & 6397 & 1.066 & 212 & 149 & 1580 & 381 \\
\hline$(80 \% \mathrm{RH}-0 \% \mathrm{RH})$ & 58.5 & 19.4 & 3.01 & 6821 & 6393 & 1.067 & 219 & 131 & 1280 & 254 \\
\hline$(70 \% \mathrm{RH}-0 \% \mathrm{RH})$ & 47.2 & 13.6 & 3.48 & 6815 & 6379 & 1.068 & 231 & 113 & 1090 & 154 \\
\hline$(50 \% \mathrm{RH}-0 \% \mathrm{RH})$ & 29.4 & 8.97 & 3.28 & 6805 & 6375 & 1.067 & 225 & 113 & 662 & 101 \\
\hline$(30 \% \mathrm{RH}-0 \% \mathrm{RH})$ & 14.8 & 5.55 & 2.67 & 6807 & 6382 & 1.066 & 225 & 137 & 333 & 76.0 \\
\hline$(10 \% \mathrm{RH}-0 \% \mathrm{RH})$ & 4.98 & 1.63 & 3.06 & 6803 & 6381 & 1.066 & 232 & 106 & 116 & 17.3 \\
\hline$(5 \% \mathrm{RH}-0 \% \mathrm{RH})$ & 1.70 & 0.761 & 2.24 & 6800 & 6365 & 1.068 & 176 & 148 & 29.9 & 11.3 \\
\hline (Bulk water) & & & & 6900 & 6518 & 1.058 & 211 & 213 & & \\
\hline$(100 \% \mathrm{RH}-95 \% \mathrm{RH})$ & 10.2 & 3.31 & 3.08 & 6881 & 6481 & 1.062 & 205 & 175 & 209 & 57.9 \\
\hline$(95 \% \mathrm{RH}-90 \% \mathrm{RH})$ & 12.9 & 3.14 & 4.11 & 6849 & 6470 & 1.059 & 216 & 171 & 279 & 53.7 \\
\hline$(90 \% \mathrm{RH}-80 \% \mathrm{RH})$ & 19.2 & 4.47 & 4.29 & 6838 & 6426 & 1.064 & 202 & 184 & 388 & 82.2 \\
\hline$(80 \% \mathrm{RH}-70 \% \mathrm{RH})$ & 13.2 & 3.33 & 3.97 & 6827 & 6420 & 1.063 & 238 & 137 & 314 & 45.6 \\
\hline$(70 \% \mathrm{RH}-50 \% \mathrm{RH})$ & 17.9 & 5.42 & 3.30 & 6830 & 6382 & 1.070 & 233 & 140 & 417 & 75.9 \\
\hline$(50 \% \mathrm{RH}-30 \% \mathrm{RH})$ & 14.5 & 3.77 & 3.84 & 6799 & 6364 & 1.068 & 227 & 107 & 329 & 40.3 \\
\hline$(30 \% \mathrm{RH}-10 \% \mathrm{RH})$ & 10.6 & 3.62 & 2.92 & 6788 & 6378 & 1.064 & 217 & 109 & 230 & 39.5 \\
\hline$(10 \% \mathrm{RH}-5 \% \mathrm{RH})$ & 2.72 & 1.71 & 1.60 & 6815 & 6378 & 1.069 & 247 & 303 & 67.2 & 51.8 \\
\hline \multirow[t]{2}{*}{$(5 \% \mathrm{RH}-0 \% \mathrm{RH})$} & 1.70 & 0.761 & 2.24 & 6800 & 6365 & 1.068 & 176 & 148 & 29.9 & 11.3 \\
\hline & & & & & & & & Total & 2263 & 458 \\
\hline
\end{tabular}

of $\mathrm{O}-\mathrm{H}$ stretching $\left(2 v_{\mathrm{OH}}\right)$ being decomposed into three components due to a nonhydrogenbonded peak centered at $7062 \mathrm{~cm}^{-1}$ and two hydrogen-bonded peaks centered at 6557 and $6427 \mathrm{~cm}^{-1}$.

It must be acceptable to continue the discussion using the results of the three component decomposition in Table III, rather than those of the two component decomposition in Table II. Namely, the band can be assigned as being composed of three components associated with three kinds of water species differing in the degree of hydrogen-bonding i.e., singly up to doubly hydrogen-bonded species, as extremes.

Figure 11 shows plots of the peak wavenumber against the referenced relative humidity for the three sub-band, sub-band I, I-II, and II. Corresponding peak wavenumbers of bulk water are also indicated by thick horizontal lines. The peak wavenumber shifts to the higher wavenumber side and approaches that of bulk water when the relative humidity increased to saturation, in general. This suggests the sorbed water most strongly interacts with the adsorbent at dryness, and interacts a little more even at saturation than in the liquid state. The results by procedure B (squares) indicate a much more rapid increase and closer approach of the wavenumber to the corresponding wavenumber of bulk water than those by procedure A (triangles), manifesting the change in the state of the sorbed water more reasonably. This is because the results by procedure $B$ are represt. ited by the increments of the sorbed water at respective humidities, while those by procedure $\mathrm{A}$ are differences between the spectra at respective humidities and dryness and too much smeared out to characterize the sorbed water as a function of the referenced humidity, especially when the humidity approaches satu- 


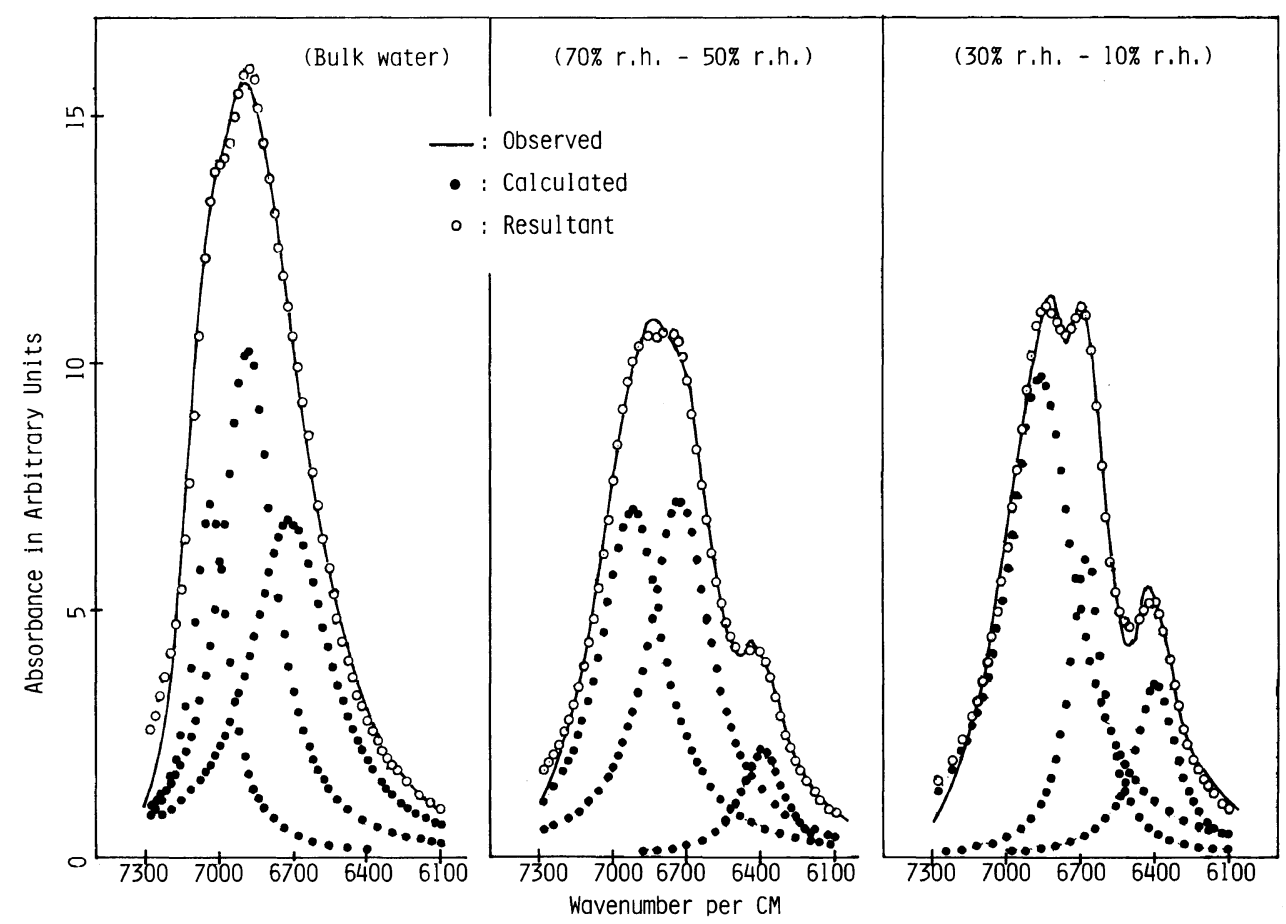

Figure 10. Decomposition of the $6900 \mathrm{~cm}^{-1}$ bands for the bulk water as well as for the differential spectra separated by procedure B into three components, sub-band I, I-II, and II in the order of descending wavenumber, by a nonlinear least square method assuming each component to be given by Lorentzian function.

ration.

Restricting the discussion only to the results by procedure $B$, it is found that the shift in the peak wavenumber of sorbed water relative to that of bulk water is 29 and $183 \mathrm{~cm}^{-1}$ at saturation and dryness, respectively, for the sub-band I, 84 and $241 \mathrm{~cm}^{-1}$ for the sub-band I-II, and 175 and $319 \mathrm{~cm}^{-1}$ for the sub-band II. That is, the shift to lower wavenumber side (red shift) becomes larger in the order of the sub-band II, sub-band I-II, and sub-band I, suggesting that the water species, which have been classified as sub-band II and assigned as most strongly interacting with each other as likely as in the iced state, also most strongly interact with nylon 6 .

The B.E.T.'s multilayer adsorption model or the Hill's multimolecular adsorption model of water cluster formation was formulated assuming that the initially sorbed water mol- ecules are most strongly adsorbed by water accessible sites to form first layer or the core portion of the water cluster. If this is the case, as widely accepted for describing the moisture sorption isotherm of hydrophilic polymers, it can be concluded that the water species classified as sub-band II and, possibly, sub-band I-II form a lesser number of layers of adsorption in the sense of B.E.T.'s multilayer adsorption or the core portion of water cluster in the sense of Hill's multimolecular adsorption.

Figure 12 compares the characterization of sorbed water by the B.E.T.'s multilayer adsorption model with that represented by the present FT-IR spectroscopy in terms of relative amounts of water species attributed to sub-bands I, I-II, and II. It may be noted semi-quantitatively that the region of Langmuir's monolayer adsorption with $n=1$ in- 
Table III. Decomposition of $6900 \mathrm{~cm}^{-1}$ band into three components of Lorentzian function

\begin{tabular}{|c|c|c|c|c|c|c|c|c|c|c|c|c|}
\hline \multirow[t]{2}{*}{ Specimen code } & \multicolumn{3}{|c|}{$\begin{array}{c}\text { Peak height } \\
\text { (relative value) }\end{array}$} & \multicolumn{3}{|c|}{$\frac{\text { Peak wavenumber }}{\mathrm{cm}^{-1}}$} & \multicolumn{3}{|c|}{$\frac{\text { Half-width }}{\mathrm{cm}^{-1}}$} & \multicolumn{3}{|c|}{$\begin{array}{c}\text { Peak area } \\
\text { (relative value) }\end{array}$} \\
\hline & $H_{1}$ & $H_{\mathrm{I}-\mathrm{II}}$ & $H_{\mathrm{II}}$ & $w_{\mathrm{ol}}$ & $w_{\mathrm{ol}-\mathrm{II}}$ & $w_{\mathrm{oII}}$ & $W_{1}$ & $W_{\text {I-II }}$ & $W_{\mathrm{II}}$ & $H_{1} \times W_{1}$ & $H_{1-I I} \times W_{\mathrm{I}-\mathrm{II}}$ & $H_{\mathrm{II}} \times W_{\mathrm{II}}$ \\
\hline$(100 \%$ RH $-0 \%$ RH $)$ & 100 & 127 & 29.5 & 6930 & 6737 & 6395 & 280 & 337 & 197 & 2800 & 4280 & 581 \\
\hline$(95 \% \mathrm{RH}-0 \% \mathrm{RH})$ & 92.7 & 110 & 27.5 & 6929 & 6735 & 6396 & 286 & 336 & 196 & 2650 & 3700 & 539 \\
\hline$(90 \% \mathrm{RH}-0 \% \mathrm{RH})$ & 87.7 & 87.6 & 27.3 & 6910 & 6716 & 6388 & 308 & 314 & 191 & 2700 & 2750 & 521 \\
\hline$(80 \% \mathrm{RH}-0 \% \mathrm{RH})$ & 84.2 & 53.8 & 24.7 & 6890 & 6697 & 6399 & 345 & 244 & 200 & 2900 & 1310 & 494 \\
\hline$(70 \% \mathrm{RH}-0 \% \mathrm{RH})$ & 71.4 & 37.0 & 21.0 & 6870 & 6685 & 6402 & 360 & 196 & 201 & 2570 & 725 & 422 \\
\hline$(50 \% \mathrm{RH}-0 \% \mathrm{RH})$ & 46.0 & 22.8 & 14.5 & 6856 & 6675 & 6397 & 352 & 161 & 212 & 1620 & 367 & 307 \\
\hline$(30 \% \mathrm{RH}-0 \% \mathrm{RH})$ & 25.3 & 11.3 & 8.70 & 6852 & 6668 & 6404 & 355 & 121 & 265 & 898 & 137 & 231 \\
\hline$(10 \% \mathrm{RH}-0 \% \mathrm{RH})$ & 6.89 & 3.43 & 3.11 & 6861 & 6669 & 6399 & 393 & 202 & 243 & 271 & 69.2 & 75.6 \\
\hline$(5 \%$ RH $-0 \%$ RH $)$ & 3.28 & 1.27 & 1.26 & 6850 & 6663 & 6393 & 177 & 88.3 & 312 & 58.1 & 11.2 & 39.3 \\
\hline (Bulk water) & & & & 7039 & 6887 & 6715 & 175 & 259 & 398 & & & \\
\hline$(100 \% \mathrm{RH}-95 \% \mathrm{RH})$ & 9.85 & 14.4 & 3.06 & 6988 & 6796 & 6487 & 216 & 338 & 202 & 213 & 487 & 61.8 \\
\hline$(95 \% \mathrm{RH}-90 \% \mathrm{RH})$ & 12.6 & 15.9 & 4.26 & 6962 & 6776 & 6512 & 250 & 333 & 379 & 315 & 529 & 161 \\
\hline$(90 \% \mathrm{RH}-80 \% \mathrm{RH})$ & 17.7 & 27.0 & 5.26 & 6955 & 6766 & 6413 & 228 & 330 & 241 & 404 & 891 & 127 \\
\hline$(80 \% \mathrm{RH}-70 \% \mathrm{RH})$ & 1.2 .7 & 17.8 & 4.44 & 6955 & 6753 & 6419 & 268 & 370 & 259 & 340 & 659 & 115 \\
\hline$(70 \% \mathrm{RH}-50 \% \mathrm{RH})$ & 20.5 & 21.0 & 6.34 & 6922 & 6730 & 6394 & 320 & 315 & 208 & 656 & 662 & 132 \\
\hline$(50 \% \mathrm{RH}-30 \% \mathrm{RH})$ & 18.8 & 14.3 & 6.24 & 6870 & 6694 & 6383 & 350 & 229 & 198 & 658 & 327 & 124 \\
\hline$(30 \% \mathrm{RH}-10 \% \mathrm{RH})$ & 16.2 & 10.0 & 5.79 & 6861 & 6679 & 6396 & 335 & 170 & 213 & 543 & 170 & 123 \\
\hline$(10 \% \mathrm{RH}-5 \% \mathrm{RH})$ & 5.23 & 1.54 & 2.33 & 6838 & 6661 & 6397 & $462^{\circ}$ & 81.7 & 451 & 242 & 12.5 & 105 \\
\hline$(5 \% \mathrm{RH}-0 \% \mathrm{RH})$ & 3.28 & 1.27 & 1.26 & 6850 & 6663 & 6393 & 177 & 88.3 & 312 & 58.1 & 11.2 & 39.3 \\
\hline
\end{tabular}




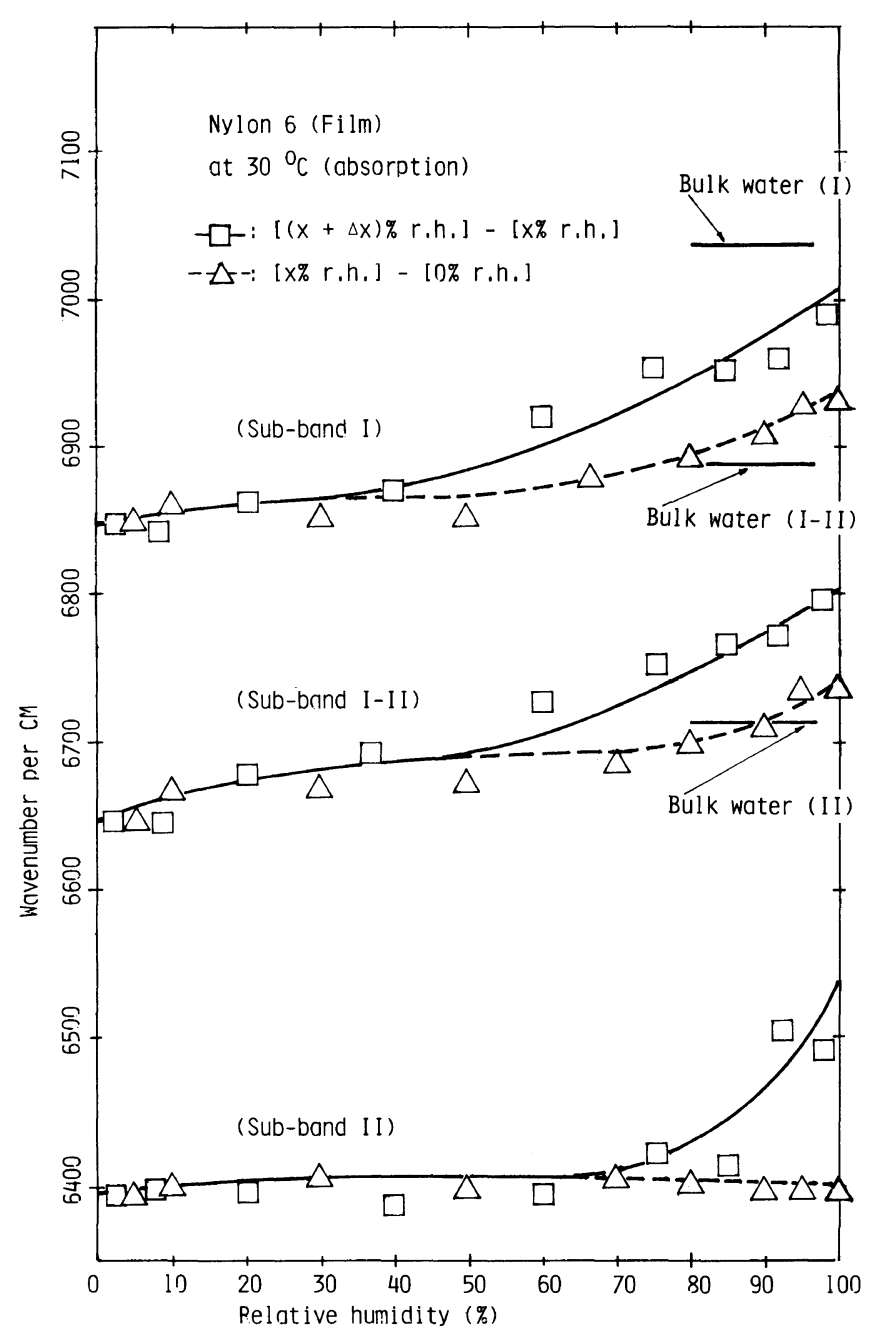

Figure 11. Plots of the peak wavenumber against the relative humidity for the three sub-bands, sub-band I, I-II, and II, decomposed from differential spectra separated by procedures A and B. Corresponding peak wavenumbers of bulk water are also shown by thick horizontal lines.

cludes all the sub-band II of ice-like water species and a part of the sub-band I-II of a little less interacted water species than the ice-like water species; that the region of B.E.T.'s multilayer adsorption with $6 \geqq n>1$ includes a part of the sub-band I-II and most of the sub-band I of singly hydrogenbonded water species; and that the region of $n>6$ includes only the water species classified to the sub-band I. It is also noted that the boundary between sub-band I and the sub-band I-II approaches the line with $n=6$ in the B.E.T.'s model at high relative humidities. Our recent broadline proton NMR study $^{1}$ has suggested that the line with $n=6$ corresponds to a transition at which the mobility of sorbed water increases up to a certain level of less interacted water, but not to a high level as comparable to the bulk water.

In contrast to the red shift of the spectrum of sorbed water relative to that of the bulk water, as investigated above, there has been 
FT-IR Spectroscopy of Sorbed Water by Nylon 6

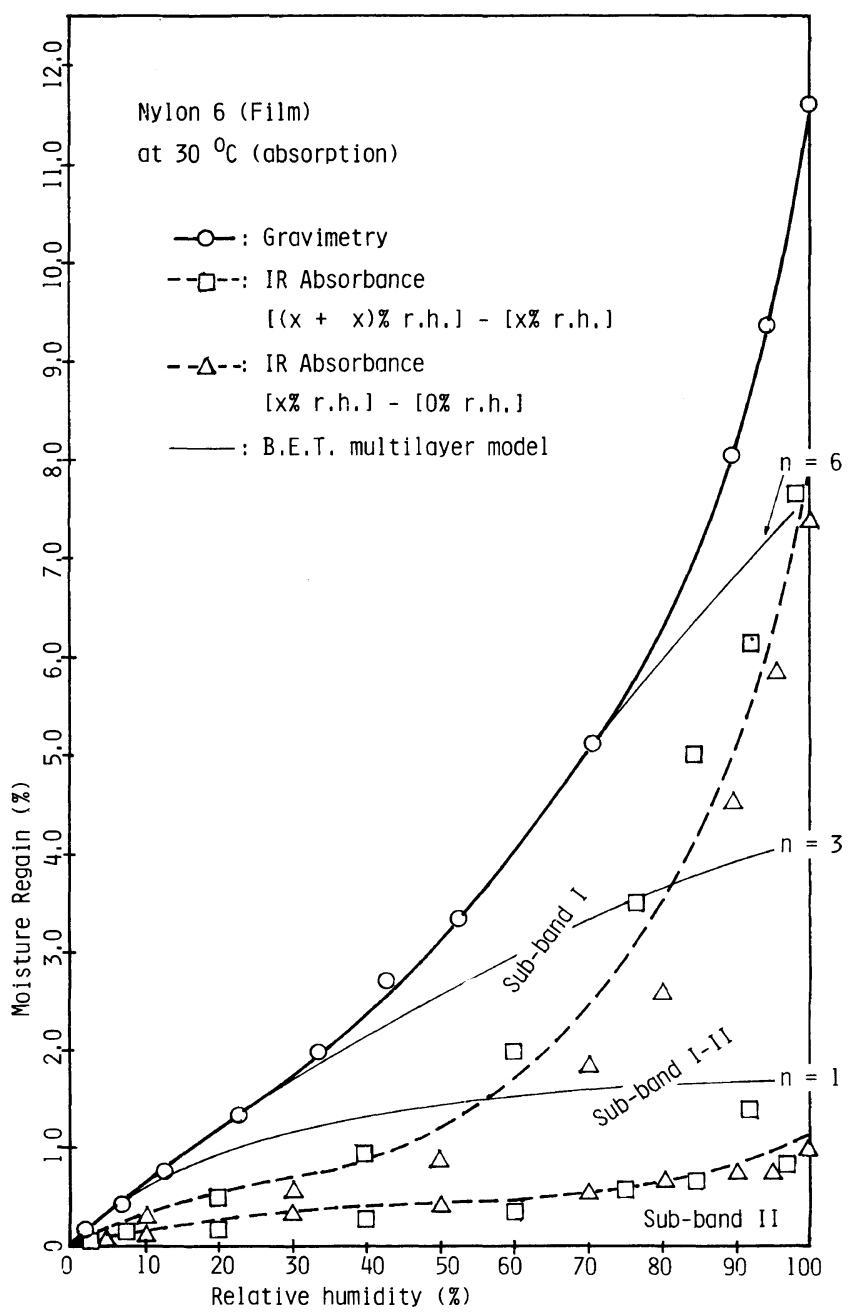

Figure 12. Comparison of the characterization of sorbed water by the B.E.T.'s multilayer adsorption model with that represented by the FT-IR spectroscopy in terms of relative amount of water species attributing to the sub-band I, I-II, and II.

some literature on polypeptide- and polyamide-water systems $\mathrm{s}^{40-42}$ reporting quite opposite (blue) shifts of the $\mathrm{O}-\mathrm{H}$ stretching band in the mid infrared range, as reviewed by Kuntz and Kauzmann. ${ }^{15}$ The problem is very serious, as criticized by Ramsden et al.,${ }^{40}$ and is quite difficult to understand. This is because, as far as the thermodynamics of moisture sorption process of these hydrophilic materials is concerned, the process is definitely of exotherm associated with the decrease in entropy of the sorbed water relative to bulk water. In other words, the excess energy of the sorbed water over the bulk water, $(T \Delta S)$, is usually found to be as large as several ten cal/gram of liquid water near dryness, to decrease rapidly with increasing humidity and then to approach zero at saturation. The value of several ten cal/gram in excess energy is roughly equal to the latent heat of the fusion of ice. These facts strongly suggest that the sorbed water should be in a much more ordered state, especially at 
dryness, than in the liquid state, but never in a disordered state as expected from the blue shift.

Acknowledgements. The authors are deeply indebted to Professor Yoshihiro Taniguchi, Department of Chemistry, Faculty of Science and Engineering, Ritsumeikan University, Kyoto, Japan, for his discussion and comments on the assignments of the near-infrared spectrum investigated.

\section{REFERENCES}

1. M. Miyagawa, K. Kohata, A. Takaoka, and H. Kawai, J. Soc. Fiber Sci. Tech., Jpn., 43, 57 (1987).

2. S. Brunauer, P. H. Emmett, and F. Teller, J. Am. Chem. Soc., 60, 309 (1938).

3. S. A. Shorter, J. Text. Inst., 15, T328 (1924).

4. T. Hill, J. Chem. Phys., 14, 263 (1946).

5. I. Langmuir, J. Am. Chem. Soc., 40, 1361 (1918).

6. K. Hoshino and K. Yumoto, Nippon Kagaku Zasshi, 70, 104 (1949).

7. H. B. Bull, J. Am. Chem. Soc., 66, 1499 (1944).

8. J. W. Rowen and R. L. Blaine, Ind. Eng. Chem., 39, 1659 (1947).

9. J. W. Rowen and R. Simha, J. Phys. Colloid Chem., 53, 921 (1949).

10. E. A. Hutton and J. Garside, J. Text. Inst., 40, T161 (1949).

11. R. Jeffries, J. Text. Inst., 51, T393 (1960); T399 (1960); T441 (1960).

12. A. Takizawa, Kolloid-Z. Z.-Polym., 222, 141, 143 (1968)

13. V. Fornes and J. Chaussidon, J. Chem. Phys., 82, 4667 (1978).

14. W. C. McCabe, S. Subramanian, and H. F. Fisher, J. Chem. Phys., 74, 4360 (1970).

15. I. D. Kuntz and W. Kauzmann, Adv. Protein Chem., 28, 239 (1974).

16. D. S. Trifan and J. F. Terenzi, J. Polym. Sci., 28, 443 (1958)

17. Y. Kinoshita, Macromol. Chem., 33, 1 (1959).

18. U. Buontempo, G. Careri, and P. Fasella, Biopolymers, 11, 519 (1972).
19. E. Bessler and G. Bier, Macromol. Chem., 122, 30 (1969).

20. R. W. Seymour and S. L. Cooper, Macromolecules, 6, 48 (1973).

21. W. J. MacKnight and M. Yang, J. Polym. Sci., Polym. Symp., 42, 817 (1973).

22. N. S. Schneider, C. P. S. Sung, R. W. Matton, and J. L. Illinger, Macromolecules, 8, 62 (1975).

23. C. S. P. Sung and N. S. Schneider, Macromolecules, 8, 68 (1975).

24. L. R. Schroeder and S. L. Cooper, J. Appl. Phys., 47, 4310 (1976).

25. C. S. P. Sung and N. S. Schneider, Macromolecules, 10, 452 (1977).

26. G. A. Scenich and W. J. MacKnight, Macromolecules, 13, 106 (1980).

27. D. Garcia and H. W. Starkweather, Jr., J. Polym. Sci., Polym. Phys. Ed., 23, 537 (1985).

28. J. W. Ellis and J. Bath, J. Chem. Phys., 6, 723 (1938).

29. J. Jakes and S. Krimm, Spectrochim. Acta, A, 24a, 35 (1971).

30. W. H. Moore and S. Krimm, Biopolymers, 15, 2439 (1976).

31. D. J. Skrovanek, S. E. Howe, P. C. Painter, and M. M. Coleman, Macromolecules, 18, 1676 (1985).

32. D. Eisenberg and W. Kauzmann, "The Structure and Properties of Water," Oxford Univ. Press, New York, N. Y., 1969.

33. W. F. Walrafen, "Water," Vol. 1, the Physics and Physical Chemistry of Water, F. Franks Ed., Plenum Press, New York, N. Y., 1972, Chapter 5.

34. W. F. Murphy and H. J. Bernstein, J. Phys. Chem., 76, 1147 (1972).

35. H. Yamatera, B. Fitzpatrick, and G. Gordon, J. Mol. Spectrosc., 14, 268 (1964).

36. I. M. Klotz, J. Colloid Interface Sci., 27, 804 (1968).

37. W. C. McCabe and H. F. Fisher, J. Phys. Chem., 74, 2990 (1970).

38. E. Greinacher, W. Lüttke, and R. Mecke, Z. Elektrochem., 59, 23 (1955).

39. K. T. Hecht and D. L. Wood, Proc. R. Soc. (London), 235, 174 (1956).

40. D. K. Ramsden, F. Wood, and G. King, J. Appl. Polym. Sci., 10, 1191 (1966).

41. I. D. Kuntz, J. Am. Chem. Soc., 94, 8568 (1972).

42. H. Kusanagi and S. Yukawa, Polym. Prepr., Jpn., 33, 748, 2807 (1984); 34, 2117, 2121 (1985). 